\title{
POSTERIOR SUBCAPSULAR CATARACTS AND MACULAR LESIONS AFTER LONG-TERM CORTICOTROPHIN THERAPY* ${ }^{\dagger}$
}

\author{
BY \\ J. WILLIAMSON \\ Ophthalmic Institute, Royal Infirmary, Glasgow \\ AND \\ T. G. DALAKOS
}

The Centre for Rheumatic Diseases, University Department of Medicine, Baird Street, Glasgow

\begin{abstract}
POSTERIOR subcapsular cataracts in patients receiving long-term oral corticosteroid therapy have been reported by several workers (Black, Oglesby, Sallmann, and Bunim, 1960; Gordon, Kammerer, and Freyberg, 1961; Giles, Mason, Duff, and McLean, 1962; Toogood, Dyson, Thompson, and Mularchyk, 1962; Crews, 1963). Increased intra-ocular pressure has also been noted (Alfano, 1963; Becker and Shaffer, 1965; Diotallevi and Bocci, 1965), and Black and others (1960) observed detachment of the retina in one eye of a rheumatoid patient with bilateral posterior subcapsular cataracts. The case presented is that of a patient with rheumatoid arthritis who had received corticotrophin by injection for $2 \frac{1}{2}$ years but no oral corticosteroid therapy, and who developed bilateral posterior subcapsular cataracts and macular degeneration.
\end{abstract}

\section{Case Report}

A 50-year-old housewife gave an 11-year history of polyarthritis affecting mainly the hands and knees. Treatment had consisted of oral salicylate therapy (mostly acetyl salicylic acid B.P.) and for the past $2 \frac{1}{2}$ years corticotrophin (Acthar gel, Armour) by intramuscular injection in an average dose of approximately 20 units per day. When first seen in October, 1965, she had no ocular symptoms and ophthalmological examination was essentially negative (see below). She had never received antimalarial therapy and there had been no known exposure to any other drug or toxic compound.

Examination.-The patient had typical rheumatoid arthritic deformities, but no subcutaneous nodules. There was mooning of the face, but no other corticosteroid side-effects were apparent. The heart, lungs, abdomen, and central nervous system were normal. The resting blood pressure was $135 / 85 \mathrm{~mm}$. Hg.

Laboratory Investigations. $-X$ rays of the joints showed erosive changes in several joints consistent with rheumatoid arthritis.

The sheep cell agglutination test was positive $1: 64$. The antinuclear factor test was weakly positive at a titre of $1: 16$ and showed homogeneous staining (Beck, Anderson, McElhinney, and Rowell, 1962). Lupus erythematosus cell preparations were negative and tests for non-toxic specific precipitins (Anderson, Gray, Beck, Buchanan, and McElhinney, 1962), thyroglobulin, thyroid "microsomal", and gastric parietal cell autoantibodies were negative. Full blood count, serum proteins, serum calcium, phosphorous, and fasting blood sugar estimations were normal. The erythrocyte sedimentation rate was $25 \mathrm{~mm}$. in the first hour.

* Received for publication August 1, 1966.

$\dagger$ Address for reprints: Eye Department, Southern General Hospital, Glasgow. 
Ocular Examination.-This was carried out on several occasions with the following results:

OCTOBER, 1965: Visual acuity with glasses was $6 / 6$ and N.5 in both eyes.

The pupils were dilated with homatropine 1 per cent. and cocaine 2 per cent. Ophthalmoscopic and slit-lamp examination revealed no abnormalities apart from minimal involutionary sclerosis of the retinal vessels. Schirmer's tear tests were negative. The patient did not have keratoconjunctivitis sicca. Intra-ocular pressure was normal.

FEBRUARY, 1966: The patient had had difficulty in reading for one month. The visual acuity with glasses was $6 / 9$ and N.5 in both eyes (N.5 partly in the right).

The pupils were again dilated and three posterior subcapsular vacuoles were detected in each lens. Over the macular areas there were indistinct "exudates". The small overlying retinal vessels appeared normal.

The dose of Acthar gel was reduced to 10 units per day.

MARCH, 1966: The fundi were photographed (Figs 1 and 2).

MAY, 1966: The patient's vision had improved slightly without any change in refraction. The lenticular opacities were unchanged, but the macular lesions showed definite edges and slight pigmentary mottling.

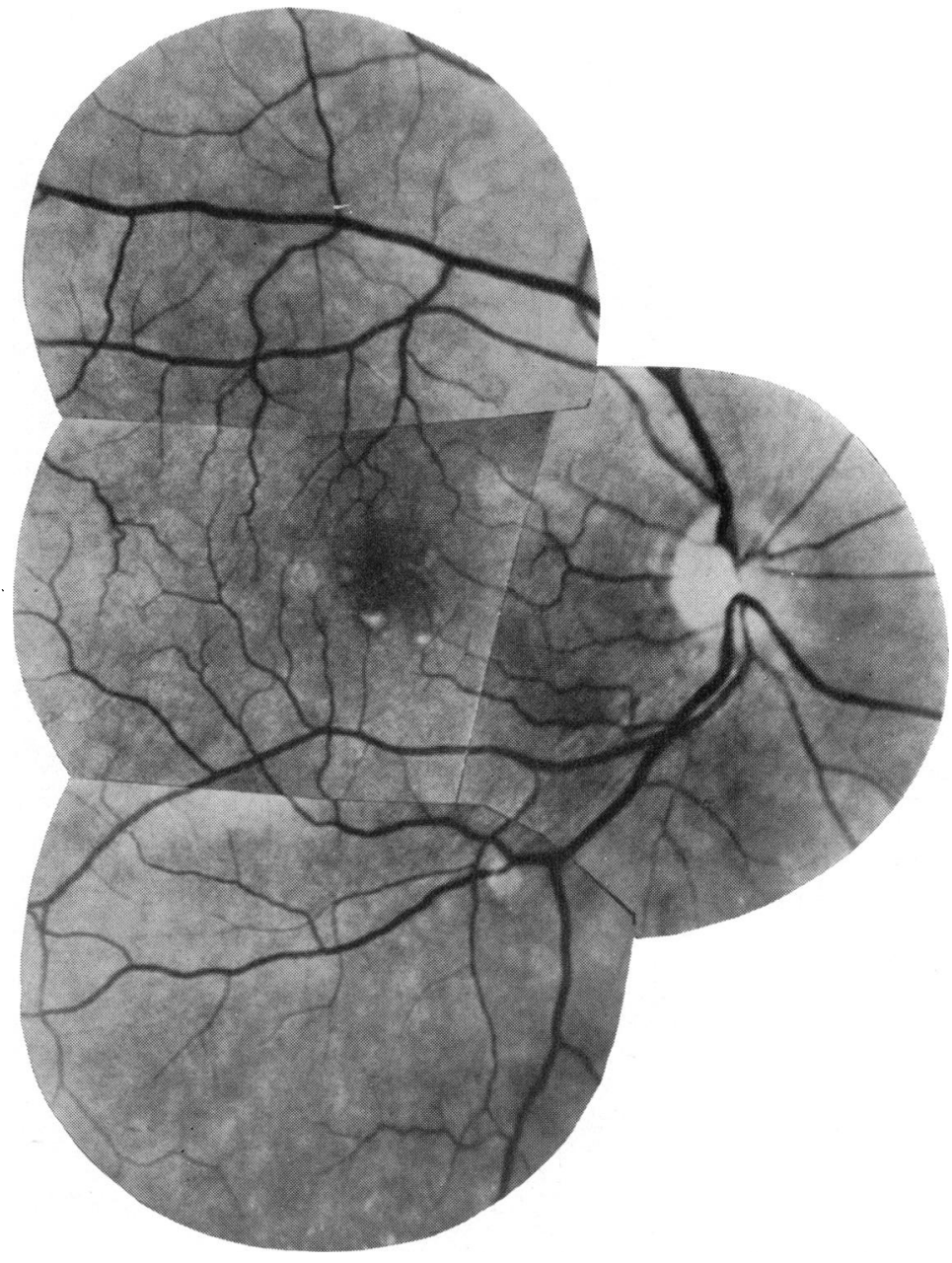

FIG. 1.-Right fundus in March, 1966. 
Family.-The patient's only sister, aged 59 years, was found to have no ocular abnormalities; her mother was too infirm to attend the hospital and there were no other relatives.

\section{Discussion}

This patient had had rheumatoid arthritis for 11 years and had received corticotrophin by intramuscular injection in an average dose of 20 units per day for $2 \frac{1}{2}$ years. Her only other treatment had been with salicylates. When she was first seen the ocular findings were essentially normal, but 5 months later while she was still receiving ACTH ocular examination revealed definite bilateral posterior subcapsular vacuoles and macular "exudates". The posterior subcapsular cataracts were consistent with those found after prolonged corticosteroid therapy. The macular degeneration was not unlike that of a presenile macular dystrophy, but the patient's only sister, aged 59 years, had normal fundi, and there was no family history suggestive of macular degeneration. A spontaneous presenile macular

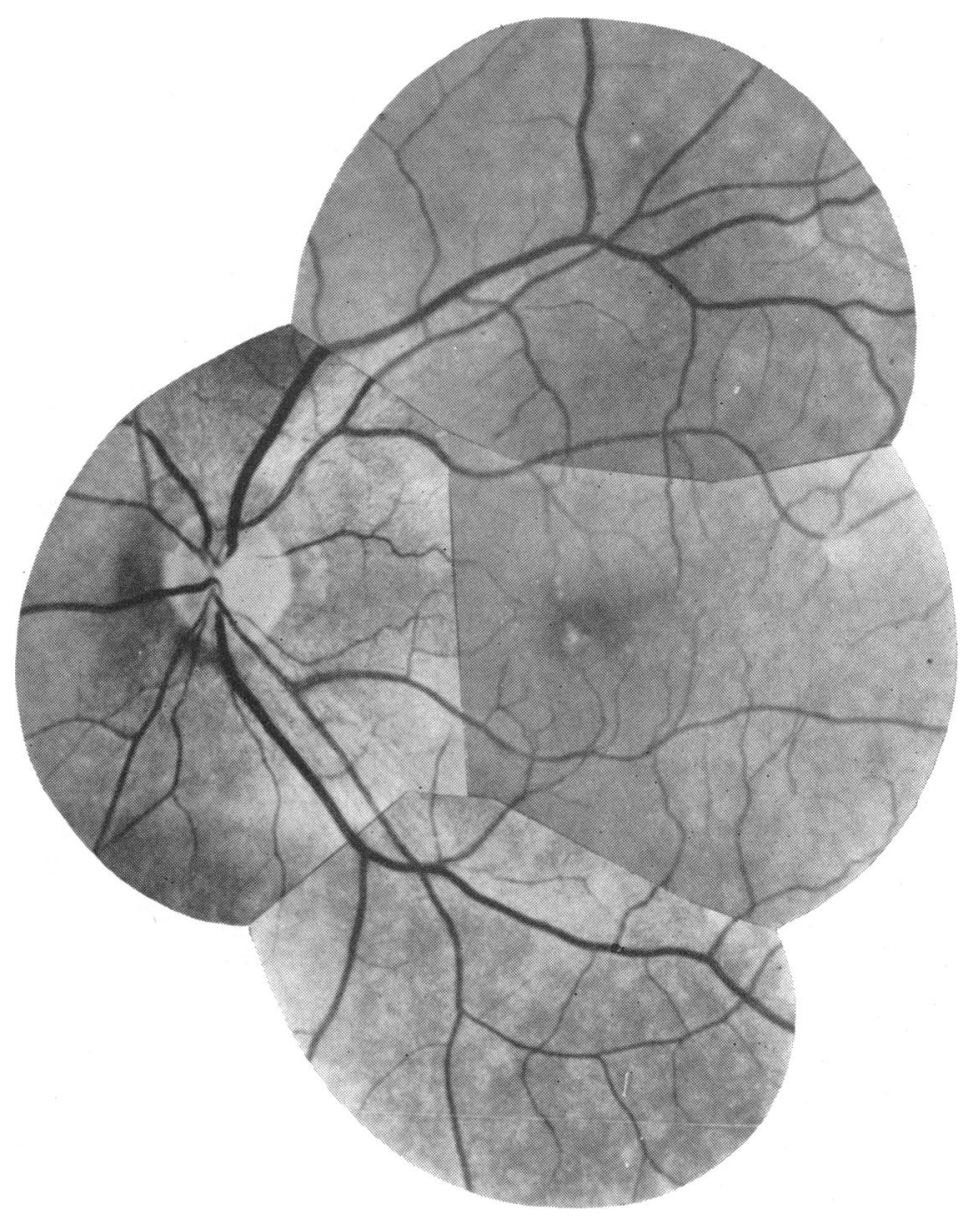

Fig. 2.-Left fundus in March, 1966. 
dystrophy cannot be excluded. We have been unable to find a record of posterior subcapsular cataracts developing in patients on long-term corticotrophin therapy, nor have they been seen by a physician of considerable personal experience in the use of this drug (Savage, personal communication). One case and possibly another in patients on Acthar gel for a similar length of time has been detected by Crews (personal communication).

The development of the cataracts in our patient raised the possibility of an iatrogenic aetiology. A little caution is required in assessing macular lesions, since posterior cortical cataracts may accompany intra-ocular lesions. However, the lens changes in this case are the classical subcapsular vacuoles seen in the early stages of steroid cataracts, and the macular lesions ceased to extend shortly after the dose of Acthar gel was reduced to 10 units per day. At the time of writing neither the cataracts nor the macular lesions have extended, although the corticotrophin therapy has had to be increased to 20 units per day for the past 6 weeks because of a relapse in the patient's arthritis.

Thus it may well be that both the cataracts and the macular lesions are iatrogenic and for this reason it is important to put this patient's case on record.

\section{Summary}

A 50-year-old woman with an 11-year history of rheumatoid arthritis developed posterior subcapsular cataracts and macular lesions after $2 \frac{1}{2}$ years of corticotrophin therapy. An iatrogenic aetiology is postulated.

Thanks are due to Dr. W. Watson Buchanan, of the Centre for Rheumatic Diseases, Glasgow, for allowing details of this patient's case to be published.

We are indebted to Mr. J. Watt, of the Photographic Department, Tennent Institute of Ophthalmology, Western Infirmary, Glasgow, for the fundus photographs.

\section{REFERENCES}

Alfano, J. E. (1963). Amer. J. Ophthal., 56, 245.

Anderson, J. R., Gray, K. G., Beck, J. S., Buchanan, W. W., and McElhinney, A. J. (1962). Ann. rheum. Dis., 21, 360.

Beck, J. S., Anderson, J. R., McElhinney, A. J., and Rowell, N. R. (1962). Lancet, 2, 575.

BeCKER, B., and ShAFFER, R. N. (1965). "Diagnosis and Therapy of the Glaucomas", 2nd ed. pp. 144, 190, 191, Mosby, St. Louis.

Black, R. L., Oglesby, R. B., Sallmann, L. von, and Bunim, J. J. (1960). J. Amer. med. Ass., 174, 166.

CREWS, S. J. (1963). Brit. med. J., $1,1644$.

Diotallevi, M., and BoccI, N. (1965). Acta ophthal. (Kbh.), 43, 524.

Giles, C. L., Mason, G. L., Duff, I. F., and Mclean, J. A. (1962). J. Amer. med. Ass., 182, 719.

GORDON, D. M., KAMMERER, W. H., and FreYBerg, R. H. (1961). Ibid., 175, 127.

Toogood, J. H., Dyson, G., Thompson, C. A., and MularchyK, E. J. (1962). Canad. med. Ass. J., 86, 52. 